\title{
Integrated 100-Gb/s ETDM Receiver
}

\author{
Colja Schubert, Rainer H. Derksen, Michael Möller, Reinhold Ludwig, Claus-Jörg Weiske, Joachim Lutz, \\ Sebastian Ferber, Andreas Kirstädter, Gottfried Lehmann, and Carsten Schmidt-Langhorst
}

\begin{abstract}
Ethernet in backbone networks has the potential to provide high-performance and cost-efficient networking solutions. Driven by the rapid growth of Ethernet traffic, it is likely that, in the transport network, the next step in terms of the data rate will be $100 \mathrm{~Gb} / \mathrm{s}$. In this paper, we report on an integrated electrical-time-division-multiplexing (ETDM) receiver for 100 / $107 \mathrm{~Gb} / \mathrm{s}$, which comprises $1: 2$ demultiplexing and clock-and-data recovery on a single chip. The ETDM receiver was tested successfully in 100- and 107-Gb/s transmission experiments over $480-\mathrm{km}$ dispersion-managed fiber.
\end{abstract}

Index Terms-Electrical-signal processing, Ethernet over wavelength division multiplexing (WDM), high-speed integrated SiGe circuits, optical communication, optical signal processing, 100-gigabit Ethernet (100 GbE).

\section{INTRODUCTION}

$\mathrm{C}$ ORE AND METRO networks provide the infrastructure for traffic aggregation in the metropolitan area and the interconnection of regions and countries at the top level of the carriers' network hierarchy.

Rising bandwidth demands-resulting from triple-play applications, storage area networks, peer-to-peer traffic, and grid computing - put network operators into a dilemma: Both the increasing share of packet traffic [1] and the request for high performance (Quality-of-Service, network resilience) require huge new investments in switching and transport technologies. Additionally, the complexity of these technologies imposes substantial financial burdens on network operators in the area of operational expenditures. At the same time, the revenues perbandwidth unit are shrinking as flat-rate contract models prevail

Manuscript received July 7, 2006; revised November 10, 2006. This work was supported in part by the Bundesministerium für Bildung und Forschung (BMBF) of the Federal Republic of Germany through the national programs "Eibone" under Contract 01BP560 and "MultiTeraNet" under Contracts 01BP155 and 01BP156.

C. Schubert, R. Ludwig, S. Ferber, and C. Schmidt-Langhorst are with the Fraunhofer Institute for Telecommunications, Heinrich-Hertz-Institut, 10587 Berlin, Germany (e-mail: colja.schubert@hhi.fhg.de; ludwig@hhi.fhg.de; carsten.schmidt-langhorst@hhi.fhg.de).

R. H. Derksen, A. Kirstädter, and G. Lehmann are with Siemens Networks GmbH \& Co. KG, MN PG NT CT 1, 81730 München, Germany (e-mail: rainer.derksen@siemens.com; andreas.kirstaedter@siemens.com; gottfried.lehmann@siemens.com).

M. Möller is with MICRAM Microelectronic GmbH, 44801 Bochum, Germany, and also with Saarland University, 66041 Saarbrücken, Germany (e-mail: michael.moeller@eus.uni-saarland.de).

C.-J. Weiske is with Siemens Networks GmbH \& Co. KG, FN PD HW 1, 81359 München, Germany (e-mail: claus-joerg.weiske@ siemens.com).

$\mathrm{J}$. Lutz is with MICRAM Microelectronic GmbH, 44801 Bochum, Germany (e-mail: joachim.lutz@micram.com).

Color versions of one or more of the figures in this paper are available online at http://ieeexplore.iee.org.

Digital Object Identifier 10.1109/JLT.2007.888489

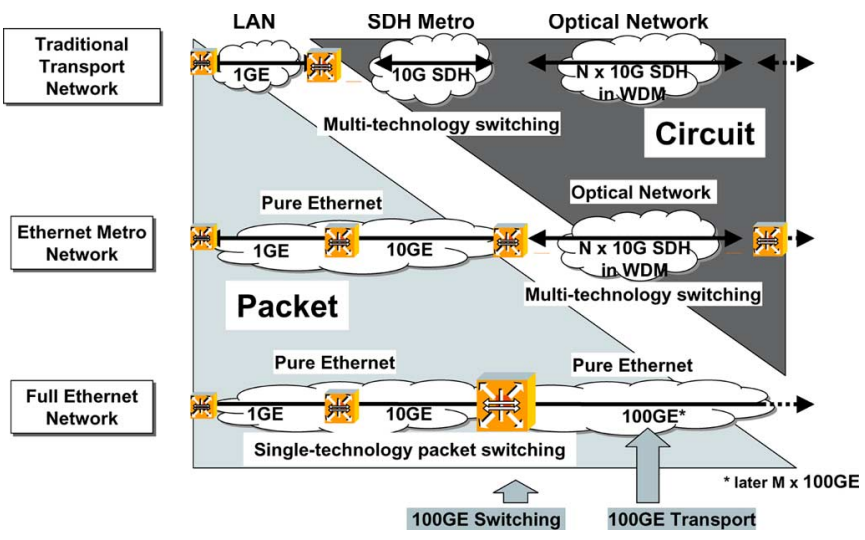

Fig. 1. Migration of Ethernet into MAN and core networks [4].

in the internet-access markets. Thus, economically efficient network architectures and new operation models are needed.

The usage of pure and possibly end-to-end Ethernet networks is a viable solution to this scenario. The industry-wide efforts and standardization activities [2], [3] to cover remaining challenges also confirm this outlook. Ethernet is generally characterized by simplicity, flexibility, interoperability, and low cost.

While Ethernet is traditionally a technology of local-area networks (LANs), continuous developments already enabled its deployment in metropolitan-area networks (MANs) Fig. 1. Recent research and standardization efforts aim at speeding up Ethernet to $100 \mathrm{~Gb} / \mathrm{s}(100 \mathrm{GbE})$, resolving scalability issues, and supplying Ethernet with carrier-grade features. For this reason, in the near future, Ethernet might become an attractive choice and serious competitor in the market of backbone networks.

In order to be suited for core networks, Ethernet needs carrier-grade features, i.e., it has to offer and implement the correct Quality-of-Service, resilience, and network-management functions. Moreover, the scalability in terms of address space and maximum transmission distance (MTD) becomes an important issue for the next Ethernet generation. In [5], it was shown that the possibility to bypass Ethernet core nodes on the wavelength-division-multiplexing (WDM) layer might lead to huge port-count savings if MTD is large enough (e.g., $15 \%$ at an MTD of $300 \mathrm{~km}$ and $30 \%$ at an MTD of $600 \mathrm{~km}$ ).

At the same time, the operational expenditures of the network architecture have to be as low as possible. This normally correlates with a small number of operated/managed objects in the network (elements and ports) and, in turn, makes high integration level and, thus, high port bandwidths indispensable. An in-depth analysis [6] demonstrated a considerable cost 
advantage of $100 \mathrm{GbE}$ in comparison to synchronous-digitalhierarchy-based solutions. The superior capital-expenditure performance results from a huge cost advantage of Ethernet devices and their fast price decline. The reduced switch and line card count in 100-GbE networks and the efficient economics of Ethernet services will be responsible for a superior operationalcost performance. For such systems, $100-\mathrm{Gb} / \mathrm{s}$ serial transmission will be preferable and installed-once electrical components are available.

It is well known that data rates above $100 \mathrm{~Gb} / \mathrm{s}$ can be transmitted over large distances (see, e.g., [6] and [7]) for $160-\mathrm{Gb} / \mathrm{s}$ transmission over deployed fiber and [8] for $160-\mathrm{Gb} / \mathrm{s}$ transmission over $4000 \mathrm{~km}$ in a ring experiment. However, the main challenge for $100 \mathrm{GbE}$ is the development of cost-efficient solutions to decrease the cost per bit and kilometer below that of lower bit-rate systems. Here, the usage of ultrafast electronic circuits instead of elaborate optical methods is a promising approach for high-capacity optical-transmission systems [9], [10]. Electronic circuitry for $40 \mathrm{~Gb} / \mathrm{s}$ is already commercially available. Transmission systems based on electrical-timedivision-multiplexing (ETDM) operating above $80 \mathrm{~Gb} / \mathrm{s}$ were reported recently [11]-[14]. In [11] and [12], the data rate was limited to $85 \mathrm{~Gb} / \mathrm{s}$ and the electrical receiver comprised a number of small single circuits requiring an additional photo diode for the clock recovery. In [13] and [14], the data rate was $107 \mathrm{~Gb} / \mathrm{s}$, but the receiver included an optical time division demultiplexer and the clock was transmitted on a separate wavelength channel. To really exploit the cost advantage of an electrical receiver compared to optical solutions, a compact integrated device is needed—preferably a single chip.

As an important step toward $100 \mathrm{GbE}$, we present in this paper an integrated ETDM receiver, comprising $1: 2$ demultiplexing (DEMUX) and clock-and-data recovery (CDR) on a single chip. The integrated ETDM receiver will be described in detail in Section II. In [15], we demonstrated this integrated ETDM receiver in a transmission experiment at a data rate of $100 \mathrm{~Gb} / \mathrm{s}$ using a return-to-zero ON-OFF-keying (RZ-OOK) optical-time-division-multiplexing (OTDM) transmitter. In Section III, we will describe this experiment in detail. In addition to [15], we also show here that the same chip is capable of operating at an increased data rate of $107 \mathrm{~Gb} / \mathrm{s}$ - the rate expected for future 100-Gb/s Ethernet-transport networks including forward error correction (FEC). Error-free performance after $480-\mathrm{km}$ dispersion-managed fiber (DMF) was achieved. This is the first demonstration of a single-chip ETDM receiver at $107 \mathrm{~Gb} / \mathrm{s}$ in a transmission experiment. Finally, this paper will be summarized in the concluding Section IV.

\section{INTEGRATED ETDM RECEIVER}

\section{A. Circuit Description}

The development of the integrated ETDM receiver chip is based on the results of a similar receiver already successfully operated in a 40-Gb/s system [16] but without on-chip phaselocked loop (PLL). A block diagram of the chip is shown in Fig. 2. It was designed for $80-\mathrm{Gb} / \mathrm{s}$ operation with FEC $(86 \mathrm{~Gb} / \mathrm{s})$ and successfully operated in transmission experi-

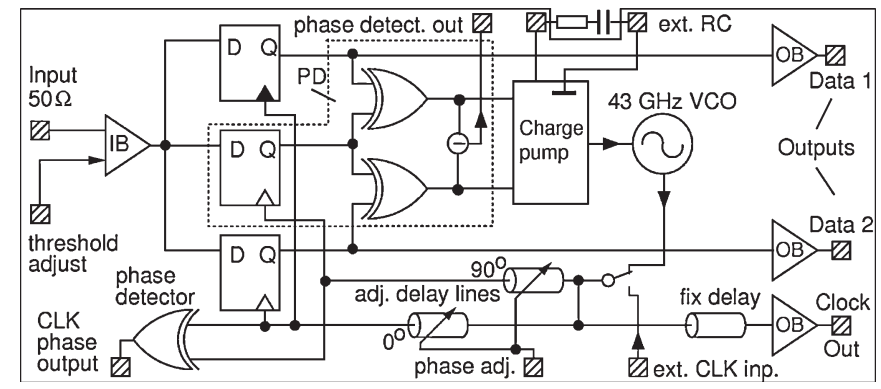

Fig. 2. Block diagram of the integrated ETDM receiver chip.

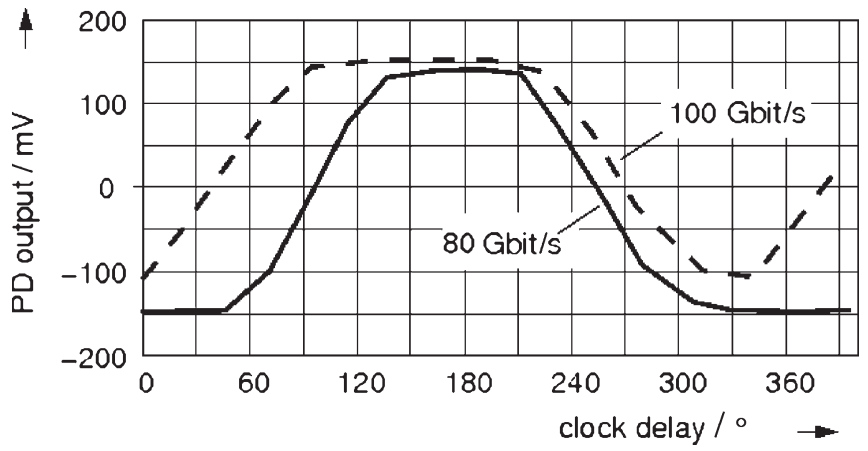

Fig. 3. PD output voltage versus clock-to-data delay in degrees for operation with 80 and $100 \mathrm{~Gb} / \mathrm{s}$.

ments with $86 \mathrm{~Gb} / \mathrm{s}$ and $100 \mathrm{~Gb} / \mathrm{s}$ [15]. The receiver chip was fabricated in a SiGe-bipolar process $(180-\mathrm{GHz}$ transit frequency, 200-GHz maximum oscillation frequency), a predecessor of Infineon Technologies' B7HF200 technology [17]. A more detailed description of the circuit including its electrical characterization is given in [18]. In addition to the information given there, it should be mentioned that the chip also incorporates a $1 / 2$ static-frequency divider, which provides half of the output clock frequency (e.g., $21.5 \mathrm{GHz}$ in the case of $86-\mathrm{Gb} / \mathrm{s}$ data signals). This function is used to simplify sampling-scope triggering and half-rate demultiplexing application.

Despite the fact that the chip was designed for $86 \mathrm{~Gb} / \mathrm{s}$, the design methodology applied enabled operation at more than $100 \mathrm{~Gb} / \mathrm{s}$. Only the internal voltage-controlled oscillator (VCO) could not be used as it was not designed for such an extremely large tuning range. However, the ETDM receiver-chip design offers the opportunity to insert an external $50-\mathrm{GHz} \mathrm{VCO}$ into the PLL. The VCO output is connected to the external clock input ("ext. CLK inp." in Fig. 2) of the chip. The feedback signal to the $\mathrm{VCO}$ is derived from the chip internally generated phase-detector (PD) signal via an external control circuit, which replaces the charge-pump circuit on the chip.

A measurement result of the PD output signal for $100 \mathrm{~Gb} / \mathrm{s}$ as well as for $80 \mathrm{~Gb} / \mathrm{s}$ is shown in Fig. 3. At $100 \mathrm{~Gb} / \mathrm{s}$, the clock-delay range in the "high" state of the curve is significantly longer than that in the low state. This asymmetry is mainly caused by a frequency-dependent difference in delay between the $90^{\circ}$ and $0^{\circ}$ delay line. While the adjusted delay causes a phase shift of approximately $90^{\circ}$ at $43-\mathrm{GHz}$ clock frequency, the phase shift increase to $50 / 43 \times 90^{\circ} \approx 105^{\circ}$ at $50 \mathrm{GHz}$. A symmetrical PD curve can be obtained by decreasing the difference in delay between the $90^{\circ}$ and the $0^{\circ}$ delay line, using 
the phase-adjustment input of the chip. Please note that the curve for $100 \mathrm{~Gb} / \mathrm{s}$ is not strictly repeating after $360^{\circ}$. This is due to a limited setting accuracy of the clock delay, since a delay of $30^{\circ}$ (one scale division on the $x$-axis) for the $100-\mathrm{Gb} / \mathrm{s}$ curve corresponds to 833 fs only.

For upcoming 107-Gb/s designs, the integration of a complete PLL with 53.5-GHz VCO appears feasible, since proper VCO operation at even higher frequencies has been reported for the same semiconductor process as used for the receiver chip [19].

\section{B. Design Concept}

In the high-speed part of the receiver, there are 44 cells running with speeds greater or equal $50 \mathrm{~Gb} / \mathrm{s}$, respectively, $50 \mathrm{GHz}$. The cells with basic functions are input amplifier, master-slaveD-flipflop (MS-D-FF), exclusive-OR, intermediate and output buffer, as well as VCO. Except VCO and input amplifier, all the other cells are used several times in the design. This holds especially for the intermediate amplifier cell (not shown in Fig. 2), which is used as a repeater amplifier (buffer) along longer transmission lines, as well as five times in each delay element (cf. [18]).

In order to minimize design time and risk, a standard cellbased design approach was used, which was also successfully applied to the design of a 100-Gb/s 2: 1 MUX [18]. In principle, in this approach, the complete design was build up from verified standard cells taken from a cell library. While this design concept is very common to high-integration designs at comparably low speed, it needs to be adapted to high-speed requirements. This is achieved by differential operation of all cells and their routing, following the design rules given in [20]. In the standard cell-based design concept applied, major areas of concern are the power level and interfaces of the cells, as described below.

\section{Cell Power Level}

Low power consumption is essential, since the transistor speed decreases if the transistor enters the region of the highcurrent effect due to a high junction temperature (cf. [20]). Also, for the sake of reliability, the width of metallization at the points of maximum current density needs to be increased significantly if the temperature rises above $110^{\circ} \mathrm{C}, \ldots, 120^{\circ} \mathrm{C}$. This increases the parasitic capacitance and, therefore, reduces the maximum speed. Therefore, already in the development phase of the library cells, the adequate power level (driving capability) of the cells needs to be determined. It is a tradeoff between the required speed and the rise in chip temperature due to power dissipation of the cells (cf. [20]). The ability of the chip to operate above $100 \mathrm{~Gb} / \mathrm{s}$ indicates that the cell power level for the originally intended operation at $86 \mathrm{~Gb} / \mathrm{s}$ could be decreased in favor of a lower power density, which is currently as high as $1.3 \mathrm{~W} / \mathrm{mm}^{2}$.

\section{Cell Interfaces}

Regardless of its function, in principle, each cell on the chip consists of a succession of load resistors $\left(R_{L}\right)$, emitter

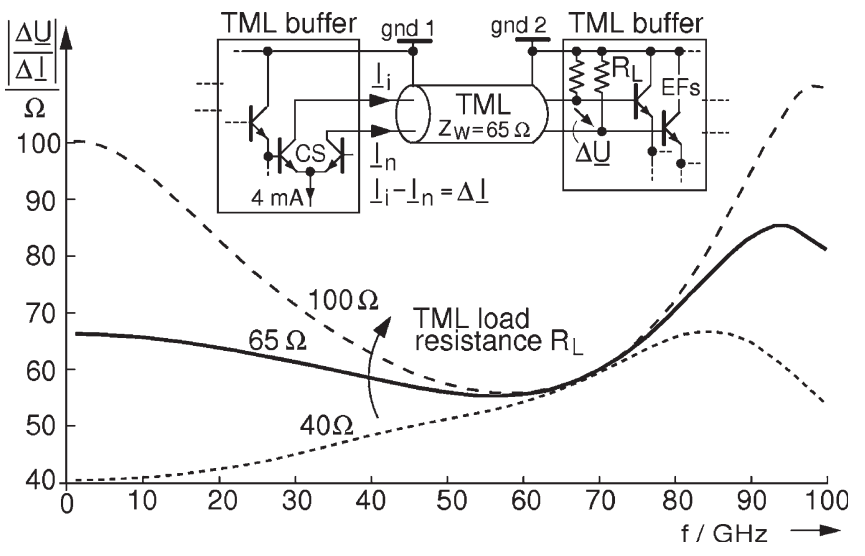

Fig. 4. Simulation result for an odd-mode transfer function of a 500- $\mu \mathrm{m}$ TML, loaded by a TML buffer with input resistors $R_{L}=40,65$, and $100 \Omega$.

followers (EF), and current switches or transadmittance stages (both referred to as CS) [20]. The load resistor is the simplest form of a transimpedance stage (TIS). In this design, it was preferred to an active TIS because, in combination with the driving CS, it shows the lower total power consumption at a comparable high cutoff frequency and output voltage swing. For the design, a source current of $4.4 \mathrm{~mA}$ for the driving CS and a load resistance of $R_{L}=65 \Omega$ was chosen.

Owing to the high output impedance of the CS in relation to $R_{L}$, this interface shows the best mismatch between source and load impedance compared to the other possible interfaces (i.e., $R_{L}-\mathrm{EF}, \mathrm{EF}-\mathrm{EF}$, or EF-CS). For the cell-based design approach, a mismatch is essential for decoupling the electrical properties of adjacent cells at the interface. It enables a cell to keep its electrical properties and performance, independent of the driving or loading cell type. Therefore, the CS- $R_{L}$ interface is used as a general $\mathrm{I} / \mathrm{O}$ interface for all cells in the cell library. The same considerations-but at a higher power consumption-would apply if an active TIS instead of $R_{L}$ were used.

\section{E. Transmission-Line Routing}

For signal routing between the cells, microstrip transmission lines (TML) are used. In order to save driver power, TMLs with the highest characteristic impedance possible in the technology are realized. From the four metallization levels available (M1 to M4), thick upper metal M4 was used to realize two lowohmic weakly coupled conductors with $12-\mu \mathrm{m}$ spacing and $2.4 \times 2.5 \mu \mathrm{m}^{2}$ cross section each. For the current-return path, layer M2 is used, which is realized together with M1 as large global ground/power supply plane. Three-dimensonal electromagnetic simulations on this TML configuration, considering mandatory voids introduced to the supply plane due to the metal-density rules, show a characteristic odd-mode impedance of $Z_{W}=65 \Omega$. In combination with the load resistor $R_{L}=$ $65 \Omega$ at a cell input, this yields a TML match at the far end.

The maximum line lengths are $280 \mu \mathrm{m}$ for each $100-\mathrm{Gb} / \mathrm{s}$ TML between input buffer (IB) and MS-D-FFs (cf. Fig. 2) and $500 \mu \mathrm{m}$ between two succeeding TML-buffers in the $50-\mathrm{GHz}$ clock distribution. Fig. 4 shows a simulation result for the oddmode transfer function of a 500- $\mu \mathrm{m}$ TML, terminated with a 


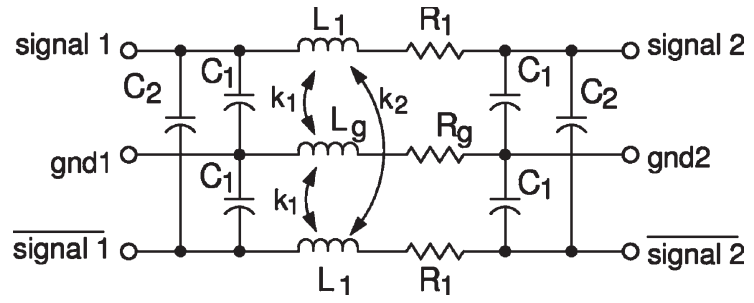

Fig. 5. TML segment model used for line lengths up to $50 \mu \mathrm{m}$.

TML buffer with input-load resistances $R_{L}$ smaller (40 $\Omega$ ), equal $(65 \Omega)$, and larger $(100 \Omega)$ than $Z_{W}$.

For the design $R_{L}=Z_{W}=65 \Omega$ was chosen because of the best compromise between flat-frequency response, high cutoff frequency, and low source current for the driving CS. Furthermore, this configuration shows nearly the same group delay for data (broadband) and clock (single frequency) signals. This allows matching of TML delays based on physical rather than on electrical TML lengths.

\section{F. Even/Odd-Mode-Signal Considerations}

In principle, a differential circuit can propagate a signal in the even as well as in the odd mode. In order to benefit from the advantages of differential operation [20], the signal is propagated throughout the entire chip in the odd mode only. Noise (e.g., switching noise or ground bounce) or fractions of the signal (e.g., due to single-ended operation at the receiver I/Os or unbalanced circuitry) in even mode are prevented from interfering the signal in odd mode by balancing the circuitry. This is obtained by a highly symmetrical layout of the library cells and signal paths.

However, for data signals [nonreturn-to-zero (NRZ)], a balanced circuit like the receiver becomes unbalanced during transients ( $\Delta I$-noise) as well as in any "digital" high or low state. Thus, signal and noise in even mode can convert to odd mode and vice versa throughout the entire chip. This may have a major influence on circuit performance or even cause unstable behavior of the circuit. Considerable simulation and optimization work was carried out in order to address the aforementioned issues adequately.

In the circuit simulation, the physical TML model of Fig. 5 was used for line lengths up to $50 \mu \mathrm{m}$. Longer lines were modeled by using this model for a sectional approximation. The model structure corresponds to the physical representation of the TML and, therefore, considers odd as well as even mode adequately.

It accounts for inductive and capacitive coupling between both conductors as well as between each conductor and the ground plane. Skin effects, as well as proximity effects, are not considered in order to reduce model complexity. Instead, the influence of these effects is considered in simulation by a simple parameter variation in the above model.

Owing to the small spacing between the signal-conductors and their high coupling to the return path (ground plane), the return path can be modeled as one conductor considering its inductive and resistive nature by the elements $L_{g}$ and $R_{g}$. This

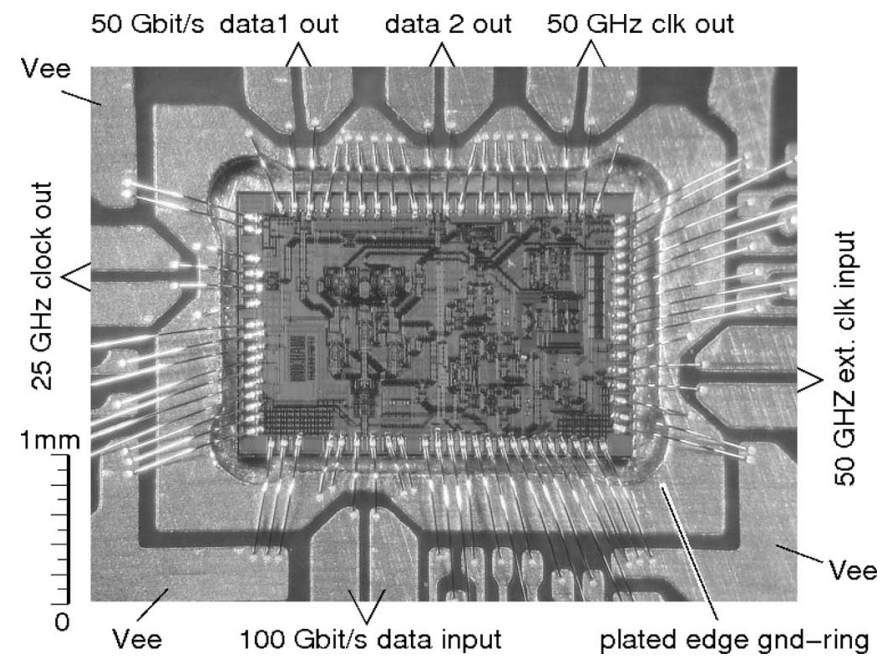

Fig. 6. Micrograph of chip assembly.

model separates ground at TML input from that at the output. This separation is mandatory to insert the model into the global ground and power-supply plane model, which consists of two large C-coupled R-L meshes. With that global ground/supplyplane model, even-mode behavior of the entire chip including assembly parasitics (e.g., ground / power-supply bond wires) can be simulated adequately.

\section{G. Chip Assembly}

Details of the chip and module assembly were already presented in [18]. Fig. 6 shows a micrograph of the receiver chip. Conventional wedge-wedge ultrasonic bonding using 17.5- $\mu \mathrm{m}$ $\mathrm{Al}$ bond-wires was used to connect the chip to the TMLs on the polytetrafluoroethylene (PTFE) substrate. Bond-wire length at the $100-\mathrm{Gb} / \mathrm{s}$ input is approximately $0.5 \mathrm{~mm}$ with a spacing of $100 \mu \mathrm{m}$. Shorter wires of about $250 \mu \mathrm{m}$ can be realized if the ground ring is left out at the data input (cf. Fig. 6).

On the other hand, in this kind of assembly technique, the ground ring is mandatory to keep the parasitic inductance to ground as small as possible. Therefore, the ground-ring metal on top of the PTFE substrate allows for multiple short ground bonds in parallel (four bonds in Fig. 6). This reduces the effective ground-bond inductance and also the effective inductance of the input bond wires via inductive coupling to the ground bonds. Furthermore, as a part of the ground ring, the edge metallization of the chip cavity provides a low-inductive current-return path from the ground bond wires on top of the substrate to the input TML ground at the substrate backside.

Thus, leaving out the ground ring at the input would increase the parasitic inductance to ground and, therefore, reduce the improvement gained by shorter signal bond wires. In addition, as a particular problem due to the single-ended interface to the photodiode (PDi), a higher inductance to ground is expected to reduce the common-mode noise-rejection ratio of the input buffer (IB) and is prone to cause stability problems.

Therefore, we decided to keep the ground ring with the long signal bond wires at the $100-\mathrm{Gb} / \mathrm{s}$ input. Measurement results at the receiver-module input, including TML and V-connectors, 


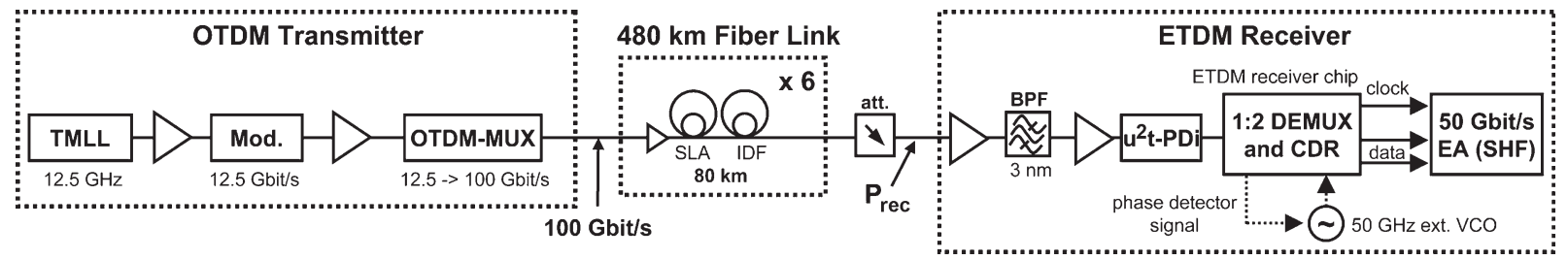

Fig. 7. Schematic depiction of the experimental setup for $100-\mathrm{Gb} / \mathrm{s}$ transmission.

show a single-ended input-return loss of $S_{11} \leq-8 \mathrm{~dB}$ up to $50 \mathrm{GHz}$. This result is subject to further optimization, applying advanced even/odd-mode-compensation techniques [21]. However, results of the transmission experiments in the next section show that even the conventional bonding technique with moderate bond-wire lengths used in this first approach is suitable for operation at $100 \mathrm{~Gb} / \mathrm{s}$.

\section{TRANSMISSION EXPERIMENTS}

The integrated ETDM receiver described in Section II was tested in transmission experiments at $100 \mathrm{~Gb} / \mathrm{s}$ and $107 \mathrm{~Gb} / \mathrm{s}$. A special transmitter based on OTDM was used to generate a high-quality RZ-OOK data signal at these high bit rates. In this section, the experimental setup and the achieved results are discussed.

\section{A. Experimental Setup}

A schematic of the experimental setup is shown in Fig. 7. It comprised an OTDM transmitter, a $480-\mathrm{km}$ fiber link, and an ETDM receiver. In the transmitter, a $12.5-\mathrm{GHz}$ semiconductor mode-locked pulse source (TMLL) emitted optical pulses (pulsewidth of $1.3 \mathrm{ps}$ and center wavelength of $1551.5 \mathrm{~nm}$ ), which were amplified and intensity modulated at $12.5 \mathrm{~Gb} / \mathrm{s}$ with a $\mathrm{LiNbO}_{3}$ Mach-Zehnder modulator. The data signal was amplified and multiplexed in an OTDM-MUX from 12.5 to $100 \mathrm{~Gb} / \mathrm{s}$. The duty cycle of the OTDM transmitter was only $13 \%$, which is significantly shorter compared to a standard RZ transmitter.

The fiber link consisted of six 80-km spans of DMF (53-km superlarge-area (SLA) fiber with $D=20 \mathrm{ps} / \mathrm{nm} / \mathrm{km}$, $27-\mathrm{km}$ inverse-dispersion fiber (IDF) with $D=-40 \mathrm{ps} / \mathrm{nm} / \mathrm{km}$, provided by OFS Denmark). The fiber link was $100 \%$ dispersion and dispersion-slope compensated. The span input power was $+7 \mathrm{dBm}$. The use of SLA-IDF allowed a higher span input power compared to standard single-mode fiber and, thus, a longer transmission distance. The average differential group delay (DGD) of the link was $1.0 \mathrm{ps}$. Due to the high bit rate, even such low DGD values would require schemes for mitigation of polarization-mode dispersion or additional system margin.

In the receiver, the data signal was optically preamplified to $+12-\mathrm{dBm}$ average power using two erbium-doped fiber amplifiers with a 3-nm bandpass filter in between and detected with a high-speed PDi provided by $u^{2} t$ photonics. The electrical $100-\mathrm{Gb} / \mathrm{s}$ signal was fed into the integrated ETDM receiver chip presented in Section II, comprising the 1:2 DEMUX and

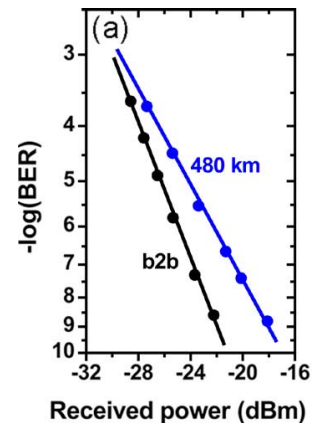

(b) Received 100 Gbit/s eye diagram

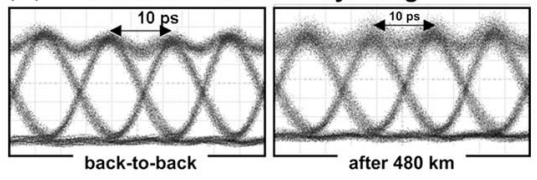

Demultiplexed 50 Gbit/s eye diagram

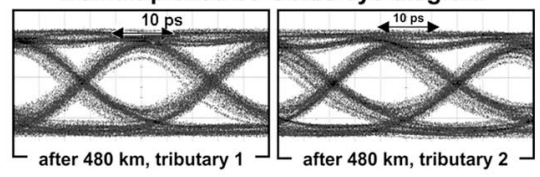

Fig. 8. (a) Bit-error measurements at $100 \mathrm{~Gb} / \mathrm{s}$ back-to-back (b2b) and after transmission over 480-km DMF, using a word length of $2^{7}-1$. (b) Top: $100-\mathrm{Gb} / \mathrm{s}$ eye diagrams at the receiver back-to-back and after $480-\mathrm{km}$ DMF. Bottom: 50-Gb/s eye diagrams after the electrical demultiplexer for both tributaries.

the CDR. As aforementioned in Section II, the internal VCO on the ETDM receiver chip was designed for $86 \mathrm{~Gb} / \mathrm{s}$ and, therefore, could not be used. For operation at $100 \mathrm{~Gb} / \mathrm{s}$ and above, an external VCO (provided by Agilent Technologies) was used instead with a control circuit driven by the PD signal generated in the receiver chip. The demultiplexed $50-\mathrm{Gb} / \mathrm{s}$ tributaries were detected with an error analyzer [(EA) provided by SHF technologies] synchronized by the recovered $25-\mathrm{GHz}$ clock signal from the receiver chip. An optical attenuator in conjunction with the preamplifier was used to vary the received power $\left(P_{\text {rec }}\right.$, as indicated in Fig. 7).

\section{B. 100-Gb/s Transmission Experiment}

The experimental results at $100 \mathrm{~Gb} / \mathrm{s}$ are shown in Fig. 8. On the left-hand side [Fig. 8(a)], the bit-error ratio (BER) measured for the $100-\mathrm{Gb} / \mathrm{s}$ data signal is shown as a function of the optical power $P_{\text {rec }}$. Error-free performance $\left(\right.$ BER $\left.<10^{-9}\right)$ was achieved back-to-back and after transmission over the $480-\mathrm{km}$ fiber link. The receiver sensitivity was $-22 \mathrm{dBm}$ back-to-back for a BER of $10^{-9}$. The required optical signal-to-noise ratio (OSNR, $0.1 \mathrm{~nm}$ ) for a BER of $10^{-9}$ was $28.6 \mathrm{~dB}$ back-to-back.

Both demultiplexed 50-Gb/s tributaries after the ETDM receiver chip were measured and the results were identical. The corresponding 50-Gb/s eye diagrams are shown in Fig. 8(b). Also, the eye diagrams of the $100-\mathrm{Gb} / \mathrm{s}$ data-signal back-toback and after transmission at the input of the receiver are plotted in Fig. 8(b). The eye diagrams at $100 \mathrm{~Gb} / \mathrm{s}$ were measured with a high-bandwidth PDi and a fast-electrical-sampling oscilloscope (70-GHz bandwidth).

Note that the OTDM-MUX in the transmitter was designed for standard synchronous-transport-module base rates and did 
not preserve the pseudorandom bit sequence at $100 \mathrm{~Gb} / \mathrm{s}$. Therefore, the EA was programmed to the expected bit pattern at a word length of 508 bit $\left(4 \times 2^{7}-1\right)$. However, the delay in the OTDM-MUX was about 47 bit at $100 \mathrm{~Gb} / \mathrm{s}$, which is sufficient to decorrelate the data pattern.

A test of the receiver chip at a longer word length of $2^{31}-1$ was not possible, because the EA could not be programmed for such a long word length. However, for the experiments at $107 \mathrm{~Gb} / \mathrm{s}$, the setup was modified and measurements at longer word lengths were possible. The experiments at $107 \mathrm{~Gb} / \mathrm{s}$ are described in the next paragraph.

\section{107-Gb/s Transmission Experiment}

The ETDM receiver chip was also tested at an increased data rate of $107 \mathrm{~Gb} / \mathrm{s}$, which corresponds to a $100-\mathrm{Gb} / \mathrm{s}$ transmission with $7 \%$ FEC overhead. For this experiment, the setup was slightly changed.

In the transmitter, the repetition rate of the TMLL was increased to $13.375 \mathrm{GHz}$ and the intensity modulator operated at $13.375 \mathrm{~Gb} / \mathrm{s}$. Also, the delays in the OTDM-MUX were adapted to enable multiplexing from 13.375 to $107 \mathrm{~Gb} / \mathrm{s}$. Please note also that at $107 \mathrm{~Gb} / \mathrm{s}$, the pseudorandom-bit sequence was not preserved. However, the delay in the OTDM-MUX at $107 \mathrm{~Gb} / \mathrm{s}$ was about 42 bit, which is still sufficient to decorrelate the data pattern.

The fiber link was unchanged compared to the $100-\mathrm{Gb} / \mathrm{s}$ experiment. The span input power was increased to $+9 \mathrm{dBm}$. Using this input power, an OSNR of $32 \mathrm{~dB}$ was achieved at the output of the transmission link. No effects from fiber nonlinearities were observed due to the use of SLA fiber and the relatively short overall transmission distance.

In the receiver, the center frequency of the external VCO was increased to $53.5 \mathrm{GHz}$ and the $50-\mathrm{Gb} / \mathrm{s}$ EA was replaced by an electrical 1:4 ETDM DEMUX with subsequent 13.375-Gb/s EA. This means that the bit-error rate at $107 \mathrm{~Gb} / \mathrm{s}$ was determined by measuring all subchannels at $13.375 \mathrm{~Gb} / \mathrm{s}$, which corresponds to the OTDM base rate in the transmitter. By measuring the bit-error rate at the OTDM base rate, programming of the EA was not necessary and longer word lengths could be used.

For optimum performance of the ETDM receiver at $107 \mathrm{~Gb} / \mathrm{s}$, the frequency-dependent delay between the $90^{\circ}$ and $0^{\circ}$ delay line on the receiver chip had to be adjusted by applying an external control voltage, as was explained in Section II-A.

The experimental results for $107 \mathrm{~Gb} / \mathrm{s}$ are shown in Figs. 9 and 10. In the upper part of Fig. 9, eye diagrams are plotted for the 107-Gb/s data-signal back-to-back and after transmission. They were measured with a high-bandwidth PDi and a 70-GHz electrical-sampling oscilloscope at the input of the receiver. The lower part of Fig. 9 shows eye diagrams of both $53.5-\mathrm{Gb} / \mathrm{s}$ tributaries, measured at the outputs of the integrated ETDM receiver.

In Fig. 10, the BER is plotted as a function of the received optical power $P_{\text {rec }}$ for $107 \mathrm{~Gb} / \mathrm{s}$ at a word length of $2^{7}-1$ and $2^{31}-1$. Each BER curve was obtained by measuring and averaging over all eight ETDM subchannels. Error-free performance $\left(\mathrm{BER}<10^{-9}\right)$ was achieved back-to-back and

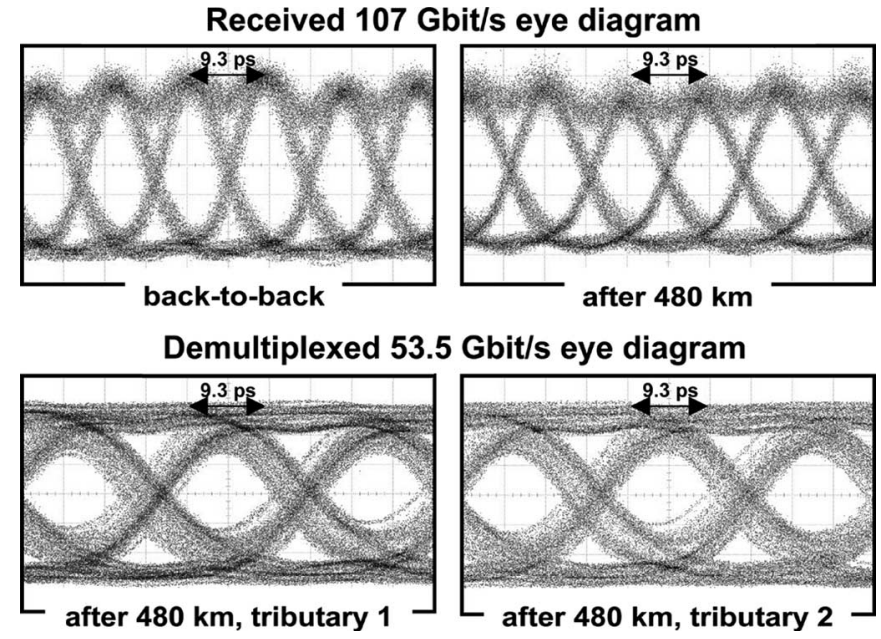

Fig. 9. Received eye diagrams at $107 \mathrm{~Gb} / \mathrm{s}$.

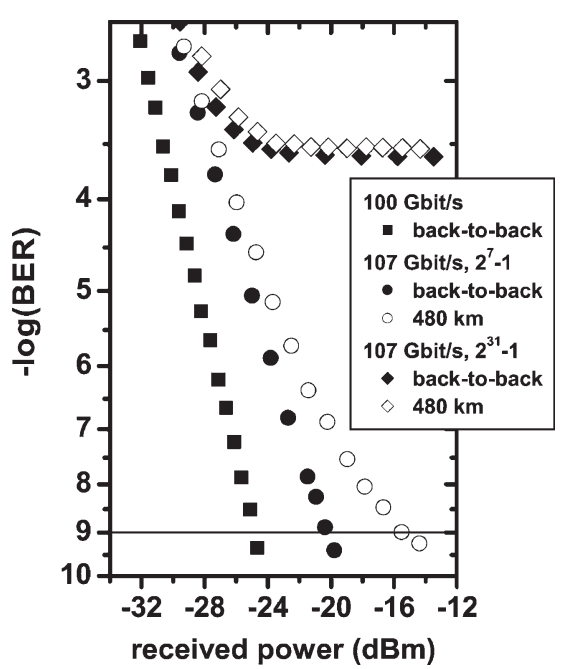

Fig. 10. Bit-error-rate measurements at 100 (word length $2^{7}-1$ ) and at $107 \mathrm{~Gb} / \mathrm{s}$ (word length $2^{7}-1$ and $2^{31}-1$ ).

over the transmission link for a word length of $2^{7}-1$. The required OSNR was $32 \mathrm{~dB}$ and $24 \mathrm{~dB}$ for a BER of $10^{-9}$ and $10^{-3}$ at $107 \mathrm{~Gb} / \mathrm{s}$, respectively. The relationship between OSNR and received power was linear within the plotted power range in the back-to-back case. The available OSNR after the transmission link was around $33 \mathrm{~dB}$, which explains the indication of an error floor in the BER measurement after the transmission link and indicates that no OSNR penalty due to transmission was present.

The receiver chip was also tested at a longer word length of $2^{31}-1$ and a performance degradation is observed (see Fig. 10) with a clear error floor around a BER of $3 \times 10^{-4}$ back-to-back and after transmission. This indicates that the chip also has bandwidth limitations toward the lower frequencies. However, a BER below $10^{-3}$ is generally regarded as the limit correctable by standard FEC circuits. Thus, an errorfree transmission $\left(\mathrm{BER}<10^{-9}\right)$ of $100 \mathrm{~Gb} / \mathrm{s}$ at $2^{31}-1$ can be expected if $7 \%$ overhead is used for FEC. The variation between the eight ETDM subchannels was almost identical for 
the two different word lengths and ranged from $8.3 \times 10^{-4}$ to $2.1 \times 10^{-3}$ for an average BER of $1 \times 10^{-3}$.

To compare the results at $107 \mathrm{~Gb} / \mathrm{s}$ and $100 \mathrm{~Gb} / \mathrm{s}$, we remeasured the back-to-back performance using the ETDM receiver chip with an optimized delay between the $90^{\circ}$ and $0^{\circ}$ delay line. The curve is also plotted in Fig. 10 for a word length of $2^{7}-1$. The back-to-back receiver sensitivity at $100 \mathrm{~Gb} / \mathrm{s}$ improved to $-25 \mathrm{dBm}\left(\mathrm{BER}=10^{-9}\right)$. This means a penalty of $4.6 \mathrm{~dB}$ at a BER of $10^{-9}$ for $107 \mathrm{~Gb} / \mathrm{s}$ compared to $100 \mathrm{~Gb} / \mathrm{s}$. This penalty is mainly attributed to bandwidth limitations in the ETDM receiver chip.

The experimental results presented in this paper were limited to investigations of the ETDM receiver using low duty-cycle RZ OTDM data signals. However, due to the limited bandwidth of the PDi in the receiver (about $70 \mathrm{GHz}$ ), the data pulses at the input of the ETDM receiver will be significantly broadened and more comparable to RZ data signals from standard ETDM transmitters. The results are, therefore, of high relevance to realsystem application. First tests using a full ETDM transmitter indicate that the performance will degrade for NRZ signals, but an error-free performance at $100 \mathrm{~Gb} / \mathrm{s}$ for a short word length $\left(2^{7}-1\right)$ can still be expected. We would like to emphasize again that the receiver chip originally was designed for $86 \mathrm{~Gb} / \mathrm{s}$, so that an even better performance can be expected after a redesign for $107-\mathrm{Gb} / \mathrm{s}$ operation.

\section{CONCLUSION}

The 100-Gb/s Ethernet will be the key enabler for future high-performance and cost-efficient backbone-network architectures. However, the main challenge for 100-Gb/s Ethernet is the development of cost-efficient solutions to decrease the cost per bit and kilometer below that of lower bit-rate systems. This target can only be reached via ultrafast electronic circuits.

We have shown the feasibility of an integrated $100-\mathrm{Gb} / \mathrm{s}$ ETDM receiver for optical transmission. The ETDM receiver was tested in optical transmission experiments at data rates of $100 \mathrm{~Gb} / \mathrm{s}$ and $107 \mathrm{~Gb} / \mathrm{s}$. The transmitter was based on OTDM and generated an RZ-OOK data signal with a duty cycle of $13 \%$, which is significantly lower compared to a standard RZETDM transmitter. Error-free performance $\left(\right.$ BER $<10^{-9}$ ) was obtained back-to-back and after transmission over $480 \mathrm{~km}$ of DMF for a word length of $2^{7}-1$. At a longer word length of $2^{31}-1$, a performance degradation is observed. An error-free transmission of $100 \mathrm{~Gb} / \mathrm{s}$ can still be expected if $7 \%$ overhead is used for FEC. The ETDM receiver, which was initially designed for $80-\mathrm{Gb} / \mathrm{s}$ operation, comprised the 1:2 DEMUX and the CDR on a single chip. This is, to the best of our knowledge, the first demonstration of a single-chip ETDM receiver at $107 \mathrm{~Gb} / \mathrm{s}$ in a transmission experiment. A redesign of the receiver chip is expected to enable an even better performance and operation at even higher bit rates.

\section{ACKNOWLEDGMENT}

The authors would like to thank Dr. Walthes from Infineon Technologies for the support within the MultiTeraNet program. They would also like to thank $\mathrm{u}^{2} \mathrm{t}$ photonics AG, SHF Com- munications Technologies AG, and Agilent Technologies for providing part of the measurement equipment.

\section{REFERENCES}

[1] IST Concertation Meeting, Sep. 2004.

[2] IEEE Draft Std. 802.1ah, Provider Backbone Bridges. [Online]. Available: http://www.ieee802.org/1/pages/802.1ah.html

[3] Metro Ethernet Forum. [Online]. Available: http://www. metroethernetforum.org

[4] G. Lehmann, A. Autenrieth, R. H. Derksen, and P. Leisching, "Die neue Ethernet-Generation: 100-Gigabit-Ethernet mit integrierten elektrisch-optischen Hochgeschwindigkeitsschaltkreisen," in Photonik, Jun. 2006, vol. 38, pp. 72-75.

[5] A. Schmid-Egger and A. Kirstädter, "Ethernet in core networks: A technical and economical analysis," in Proc. HPSR, Poznan, Poland, Jun. 2006, p. 6.

[6] J. P. Turkiewicz, E. Tangdiongga, G. D. Khoe, H. de Waardt, W. Schairer, H. Rohde, G. Lehmann, E. S. R. Sikora, Y. R. Zhou, A. Lord, and D. Payne, "Field trial of $160 \mathrm{~Gb} / \mathrm{s}$ OTDM add/drop node in a link of $275 \mathrm{~km}$ deployed fiber," presented at the Optical Fiber Commun. Conf., Los Angeles, CA, 2004, Paper PDP1.

[7] S. Vorbeck, R. Leppla, W. Weiershausen, M. Schneiders, and E. Lach, "Long-haul field transmission experiment of $8 \times 170 \mathrm{~Gb} / \mathrm{s}$ over $421 \mathrm{~km}$ installed legacy SSMF fibre infrastructure," presented at the Eur. Conf. Optical Commun., Glasgow, U.K., 2005, Paper We 3.2.1.

[8] S. Weisser, L. Raddatz, A. Benz, R. Ludwig, S. Ferber, C. Börner, and H. G. Weber, "Single-channel $170 \mathrm{~Gb} / \mathrm{s}$ transmission up to $4000 \mathrm{~km}$ using dispersion-managed fibre spans and all-Raman amplification," presented at the Eur. Conf. Optical Commun., Glasgow, U.K., 2005, Paper We 3.2.3.

[9] M. Duelk, "Next generation $100 \mathrm{~Gb} / \mathrm{s}$ ethernet," presented at the Eur. Conf. Optical Commun., Glasgow, U.K., 2005, Paper Tu 3.1.2.

[10] W. S. Lee, "80+ Gb/s ETDM Systems implementation: An overview of current technologies," presented at the Optical Fiber Commun. Conf., Anaheim, CA, 2006, Paper OTuB3.

[11] K. Schuh, B. Junginger, H. Rempp, P. Klose, D. Rösener, and E. Lach, "85.4 Gb/s ETDM transmission over $401 \mathrm{~km}$ SSMF applying UFEC," presented at the Eur. Conf. Optical Commun., Glasgow, U.K., 2005, Paper Th 4.1.4.

[12] K. Schuh, B. Junginger, E. Lach, S. Vorbeck, R. Leppla, and M. Schneiders, " $8 \times 85.4 \mathrm{~Gb} / \mathrm{s}$ WDM field transmission over $421 \mathrm{~km}$ SSMF link applying an $85.4 \mathrm{~Gb} / \mathrm{s}$ ETDM receiver," presented at the Eur. Conf. Optical Commun., Glaswog, U.K., 2005, Paper We 2.2.2.

[13] P. J. Winzer, G. Raybon, and M. Duelk, "107-Gb/s optical ETDM transmitter for $100 \mathrm{G}$ ethernet transport," presented at the Eur. Conf. Optical Commun., Glasgow, U.K., 2005, Paper Th 4.1.1.

[14] G. Raybon, P. J. Winzer, and C. R. Doerr, " $10 \times 107 \mathrm{~Gb} / \mathrm{s}$ electronically multiplexed and optically equalized NRZ transmission over $400 \mathrm{~km}$," presented at the Optical Fiber Commun. Conf., Anaheim, CA, 2006, Paper PDP32.

[15] R. H. Derksen, G. Lehmann, C.-J. Weiske, C. Schubert, R. Ludwig, S. Ferber, C. Schmidt-Langhorst, M. Möller, and J. Lutz, "Integrated $100 \mathrm{~Gb} / \mathrm{s}$ ETDM receiver in a transmission experiment over $480 \mathrm{~km}$ DMF," presented at the Optical Fiber Commun. Conf., Anaheim, CA, 2006, Paper PDP37.

[16] W. Bogner, E. Müllner, F. Znidarsic, M. Möller, H.-M. Rein, C.-J. Weiske, and E. Gottwald, "A $40 \mathrm{~Gb} / \mathrm{s}$ SiGe bipolar chipset for terabit optical networks," in Proc. IEE Semin. High Performance Semicond. Devices and Circuits Commun., London, U.K., 2000, p. 2.

[17] J. Böck, H. Schäfer, H. Knapp, K. Aufinger, M. Wurzer, S. Boguth, T. Böttner, R. Stengel, W. Perndl, and T. F. Meister, "3.3 ps SiGe bipolar technology," in IEDM Tech. Dig., 2004, pp. 255-258.

[18] U. Dümler, M. Möller, A. Bielik, T. Ellermeyer, H. Langenhagen, W. Walthes, and J. Mejri, " $86 \mathrm{~Gb} / \mathrm{s}$ receiver module with high sensitivity for $160 \times 86 \mathrm{~Gb} / \mathrm{s}$ DWDM system," Electron. Lett., vol. 42, no. 1, pp. 2122, Jan. 2006

[19] H. Li, H.-M. Rein, and M. Schwerd, "SiGe VCOs operating up to $88 \mathrm{GHz}$, also suited for automotive radar sensors," Electron. Lett., vol. 39, no. 18, pp. 1326-1327, Sep. 2003.

[20] H.-M. Rein and M. Möller, "Design considerations for Very-High-Speed Si-Bipolar IC's Operating up to $50 \mathrm{~Gb} / \mathrm{s}$," IEEE J. Solid-State Circuits, vol. 31, no. 8, pp. 1076-1090, Aug. 1996.

[21] M. Möller, "Design and optimization of monolithic integrated broadband amplifiers in Si-bipolar technology for optical transmission systems," Dr.-Ing. thesis, Ruhr-Universität Bochum, Fakultät für Elektrotechnik, Bochum, Germany, 1999. 


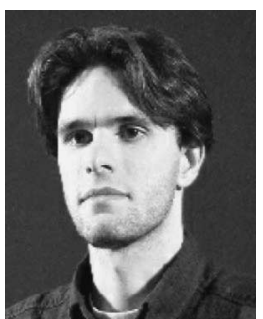

Colja Schubert was born in Berlin, Germany, in 1973. He received the Dipl.-Phys. and Dr.rer.nat. degrees in physics from the Technische Universität, Berlin, in 1998 and 2004, respectively.

He was an exchange student at the Strathclyde University, Glasgow, U.K., from 1996 to 1997. During his diploma thesis in 1997-1998, he worked at the Max-Born Institute for Nonlinear Optics and Short Pulse Spectroscopy, Berlin. Since 2000, he Fraunhofer Institute for Telecommunications, Heinrich-Hertz-Institut, Berlin, doing research work on high-speedtransmission systems and all-optical signal processing. He is currently the Head of the "High-Speed Transmission" group.

Dr. Schubert is a member of the German Physical Society. has been a member of the scientific staff with the

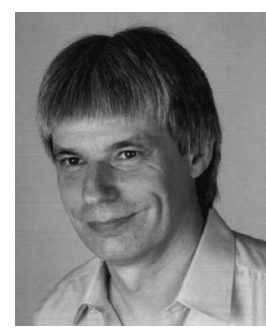

Reinhold Ludwig was born in Lahnstein, Germany, in 1952. He received the Ing.-Grad. degree from the Fachhochschule Koblenz in 1974 and the Dipl.-Ing. and Dr.-Ing. degrees from the Technical University Berlin, Berlin, Germany, in 1985 and 1993, respectively.

$\mathrm{He}$ joined the Heinrich-Hertz-Institut (HHI), Berlin, in 1985, where he is involved in research on photonic components and systems. He worked as a Visiting Scientist at Nippon Telephone and Telegraph Company in 1991 and at Bell Labs in 1993. Since 1985, he has been the Author and Coauthor of more than 300 scientific papers and has been the holder of several patents. In 1996, he founded the first HHI spin-off company (LKF Advanced Optics GmbH) and served as the Chief Executive Officer until the merger of LKF and u2t Innovative Optoelectronic Components $\mathrm{GmbH}$ in 2001.

Dr. Ludwig is a member of the Verein Deutscher Elektrotechniker (VDE). In 1999, his group received the Philip Morris Research Award, and he was nominated for the Innovation Award of the German Bundespraesident.

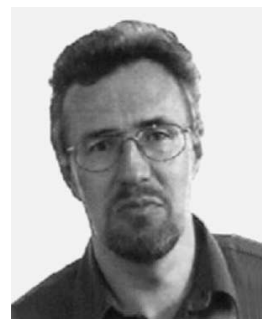

Claus-Jörg Weiske was born in Leipzig, Germany, in 1951. He received the Dipl.-Ing. degree in electrical engineering from the Technische Universität München, Munich, Germany, in 1977.

In the late 1970s, he was acquainted with first optical speech-transmission systems using $\mathrm{HeNe}$ lasers and direct acoustooptical modulation and demodulation at Siemens research laboratories, Munich. In 1988, he joined the advanced technology team, where he developed the high-frequency parts of optical transponders and investigated different modulation schemes in dense wavelength division multiplexing (DWDM) systems. Backnang, Germany, where he mainly worked on integrated circuits for highest frequencies or bit rates for optical-fiber-transmission systems and radio-link systems. From 1999 to 2001, he was design manager in the development of integrated circuits for optical-fiber-transmission systems at Infineon Technologies, Munich, Germany. From 2001 to 2006, he was with Siemens AG and is currently with Siemens Networks GmbH \& Co. KG, Munich, mainly working in a project for the demonstration of an electrical $80-\mathrm{Gb} / \mathrm{s}$ receiver as overall project director since 2003. After the end of this project in fall 2005, he worked as Project Coordinator for the $100-\mathrm{Gb} / \mathrm{s}$ Ethernet-transmission activities. He has authored or coauthored some 24 publications, mainly in the area of high-speed integrated circuits and related topics.

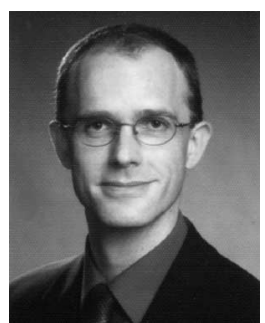

Michael Möller was born in Bebra, Germany, in 1965. He received a Dipl.-Ing. degree from FHGießen-Friedberg, Germany, in 1987 and the Dipl.Ing. and Dr.-Ing. degrees in electrical engineering from the Ruhr-University Bochum (RUB), Bochum, Germany, in 1991 and 1999, respectively.

In 1991, he joined AG Halbleiterbauelemente (Prof. Dr. H.-M. Rein) at the RUB, where he worked on the development of high-speed demonstrator circuits in bipolar technology for communication systems up to $60 \mathrm{~Gb} / \mathrm{s}$. In 1999, he joined MICRAM Microelectronic GmbH. As the company's CTO, he focuses on the activities on turnkey development of integrated high-performance ASICs, mainly for the communication and automated test equipment (ATE) market. Since 2005, he has been holding the Chair of electronics and circuits at Saarland University, Saarbrucken, Germany, where he continues research on design and optimization of integrated high-performance circuits.

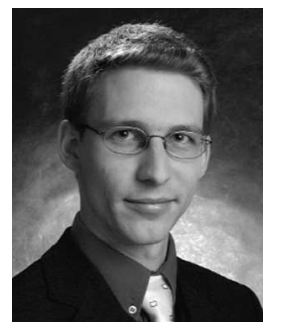

Joachim Lutz was born in Kleve, Germany, in 1969. He received the Dipl.-Ing. degree from the RuhrUniversity Bochum, Bochum, Germany, in 2000.

$\mathrm{He}$ worked for the research group Semiconductor Devices and joined MICRAM Microelectronic $\mathrm{GmbH}$, Bochum, in 2000, where he was engaged in research, design, and measurement tasks.
Sebastian Ferber was born in 1975. He received the degree in physics from Technische Universität, Berlin, Germany, in 2001. He joined the OTDM group at the Heinrich-Hertz-Institut (HHI), Berlin, where he is currently working toward the Ph.D. degree with a thesis on the topic of advanced modulation formats in high-speed-transmission systems.

$\mathrm{He}$ is currently with the Fraunhofer Institute for Telecommunications, HHI, Berlin. He is author or coauthor of more than 40 papers and has received several awards. 


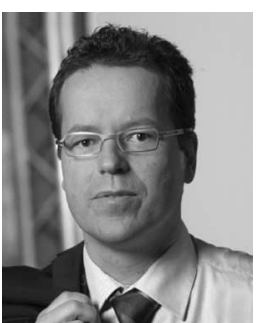

Andreas Kirstädter received the Dipl.-Ing., Dipl.Wirtsch.-Ing., and Dr.-Ing degrees from Munich University of Technology, Munich, Germany, in 1990, 1992, and 1997, respectively, all in electrical engineering and economics.

From 1991 to 1997 , he was with the Institute for Communication Networks, Munich University of Technology, where he worked on research topics in the area of high-speed networking, wavelengthdivision-multiplexed networks, and simulation, analytical modeling, and high-speed hardware design. In 1997, he joined Siemens Corporate Technology, Munich, where he was leading the high-speed and optical networks research. Currently, he is responsible for the "Optical Networks and Transmission" department within Siemens Networks GmbH and Company KG. Since 2000, he has been lecturing on "Simulation of Communication Networks" at Munich University of Technology. His current research interests include carrier-grade Ethernet, photonic networks, control-plane architectures, hardware implementation of communication protocols, network resilience, mobility, quality of service, and multimedia concepts for the Internet.

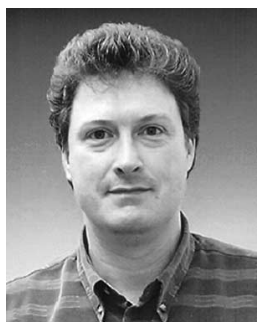

Gottfried Lehmann was born in Freiburg, Germany, in 1970. He studied physics at the Universities of Freiburg and Heidelberg, Germany. He received the $\mathrm{Ph} . \mathrm{D}$. degree in the field of ultrasonic and superhard material from the University of Heidelberg in 2001.

He joined Siemens AG, Information and Communication Networks, Munich, Germany, where he was working in the Advanced Transport System Department and was investigating the physical limitations of optical-transport systems. In 2003, he transferred to the Information and Communication Department of Siemens Corporate Technology. He led the European Union funded 160-Gb/s IST project FASHION and was the Work Package Leader of the European Commission (EC)-funded integrated project NOBEL. Since June 2006, he has been responsible for the optical-system performance of the Siemens Surpass hiT7500 wavelength-division-multiplexed ultralong-haul system. He has authored or coauthored more than 30 scientific publications.

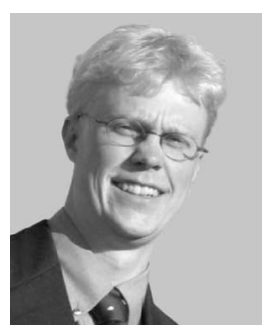

Carsten Schmidt-Langhorst was born in Berlin, Germany, in 1972. He received the Dipl.-Phys. and the Ph.D. degrees (Dr.rer.nat.) in physics from the Technical University of Berlin in 1997 and 2004, respectively.

Since 1998, he has been with the Fraunhofer Institute for Telecommunications, Heinrich-HertzInstitut, Berlin, where he has been engaged in alloptical transmission, processing, and detection of optical data signals at a picosecond time scale, and in particular, all-optical sampling techniques. He is currently heading several projects in the field of ultrafast-optical-transmission technology.

Dr. Schmidt-Langhorst is a member of the Deutsche Physikalische Gesellschaft. He received the Philip Morris Research Award in 1999. 